\title{
Water productivity: a basic tool for sustainable irrigation
}

\author{
M. N. Nimah, S. N. Moukarzel, M. R. Darwish, N. Farajalla \\ \& I. Bashour \\ Land and Water Resources Department, \\ Faculty of Agricultural and Food Sciences, \\ American University of Beirut, Lebanon
}

\begin{abstract}
The rapid population, economic and standard of living growth with the global climate changes is increasing the per capita demand on water. This increase in water demand is resulting in less available fresh water supply for agriculture. To sustain irrigated agriculture, better water management is necessary at all levels. Water supply in the Middle East and North Africa region (MENA) is unequally distributed in space and time. This region has among the lowest per capita water supply in the world. On the other hand, the intensive extraction and use of water without proper planning and provisions for the protection of their water resource has led to serious water pollution. Agriculture consumes $70-80 \%$ of water in this region. This leads to a fundamental problem for water-short countries that should manage between their renewable water resources and their capacity for food production. Water-short countries do import food commodities, which has imbedded water called "virtual water". The aim of this paper is to present a model with the general objective to maximize water productivity (monitory units per cubic meter of water). The mathematical model resulted in a maximum water productivity of $6.92 \$ / \mathrm{m}^{3}$ with eight crops out of 43 crops grown on site. The remaining 35 crops induced a saving $3,408 \mathrm{~m}^{3} / \mathrm{ha}$, which equals the virtual water. Three sets of scenarios were tested. First a decrease in available water from $100 \%$ to $50 \%$ showed a decrease in the objective function value from 6.92 to $4.727 \$ / \mathrm{m}^{3}$, second a decrease in on farm crop prices by 10,20 and $40 \%$ caused decreases in the objective function value by $4.8 \%, 9.66 \%$ and $20.29 \%$ respectively, while an increase in prices increased the objective function value and third an imposition of certain crops in the project area decreased water productivity.
\end{abstract}

Keywords: water productivity, virtual water, water use efficiency, crop yield. 


\section{Introduction}

The rapid population, economic, and standard of living growth with the global climate changes is increasing the per capita demand on water. This increase in water demand (both in domestic and industrial water supply) is resulting in less available fresh water supply for agriculture. So, the area of land irrigated per capita is decreasing. Proper water resources management becomes essential in order to optimally allocate water among domestic, industrial and agricultural domains. Meanwhile, a major issue is still disregarded, this issue being whether there will be enough water for the next generations.

Water supply in the Middle East and North Africa (MENA) region is unequally distributed in space and time, both at regional and international level. The Southern Mediterranean and Middle East sub-regions have among the lowest per capita amount of water supply in the world. It is estimated that $7 \%$ of the entire Mediterranean population (28 million persons) lie below the severe scarcity line of $500 \mathrm{~m}^{3} /$ year per capita and another $29 \%$ (115 million persons) are below the poverty line of $1000 \mathrm{~m}^{3} /$ year per capita as defined by the United Nations. In certain countries, exploitation indexes of renewable natural fresh water resources have reached and exceeded 100\%. In the Mediterranean countries, agriculture consumes $70-80 \%$ of water; the remaining is shared between domestic and industrial uses. The Food and Agricultural Organization estimates that an overall expansion of $2.25 \%$ per year in irrigation is needed to meet the word food demand; yet expansion in irrigation has slowed down to less than $1 \%$ per year [1].

Will humanity face water scarcity? Will the "blue gold" be scarce, expensive and source of conflicts between states? This increase in number of inhabitants will have to share the same amount of water that we use nowadays. There is a major threat that the water available may be inadequate to meet growing food demands particularly in water short countries (Rosegrant et al [2]). Two other threats should be considered. The first one is pollution arising from wastewater, agricultural pesticides, fertilizers, and industrial wastes discharged to rivers and the ground water. In this case, one cubic meter of polluted water renders 8 to 10 $\mathrm{m}^{3}$ unusable. The other threat that is difficult to quantify, is global warming. It could modify the hydrologic systems of various regions of the world. This leads to a fundamental problem for water-scarce countries that should balance between their renewable water resources and their capacity for food production. Every year, farmers and traders in the MENA move volumes of virtual water equivalent to the flow of the Nile into Egypt, or about $25 \%$ of the region's total available freshwater through the import of food and fibre (Allan [3]).

Virtual water and water productivity combine agronomic and economic concepts, with emphasis on water as a key factor of production. The agronomic component addresses the amount of water used to produce crops, while the economic component involves the opportunity cost of water, which is its value in other uses that may include production of alternative crops. The virtual water perspective is consistent with the concept of integrated water management, in which many aspects of water supply and demand are considered when 
determining the optimal use of limited water resources (Bouwer [4]). The net productivity or gross margin is the value of crop productivity $\left(\mathrm{MU} / \mathrm{ha}^{-1}\right.$ or $\mathrm{MU} / \mathrm{m}^{3}$ ) minus all applicable production costs. For the purpose of this study, water productivity is defined as monetary units per unit of water $\left(\mathrm{MU} / \mathrm{m}^{3}\right)$. The current approach for demand management in irrigated agriculture recommended by international organizations and governmental agencies is to adopt 'watersaving' irrigation methods such as localized irrigation. Localized irrigation is not a miracle technology, since excellent as well as, poor results were obtained. Moreover, most farmers and irrigation operators lack the understanding of the soil-plant-water-climatic relationship in order to better operate and manage this new adopted technology (Nimah et al [5]).

The theme of an alternative water demand management is to have more "monetary value per drop of water". To achieve this alternative, the virtual water and water productivity concepts are combined as an approach to deal with water scarcity (Moukarzel and Nimah [6]). This new approach does prioritize and arrange in a descending order what food commodities to import and what crops to grow locally. The general objective of this study is to combine and maximize the virtual water and water productivity concepts.

The specific objectives of this study are to (a) Develop a mathematical model to optimize the crops to be produced by maximizing water productivity per unit water i.e. monetary units per unit of water and (b) Estimate the volume of virtual water within the context of national water need and water availability for future strategic planning of water management.

\section{Methodology}

\subsection{Model description}

A linear mathematical model is developed to solve the problem of how best to allocate water among different crops to have the best combinations of net revenue per cubic meter of water and quantity of water under conditions of limited water available. In addition the model satisfies the different constraints imposed by the decision manager of the irrigation project. The optimization model developed in this study required input data generated from a set of implicit equations. This input data consist of crop water requirements, crop water demand, and water use efficiency.

\subsection{Objective function}

The objective function of the model is to maximize the water productivity $\left(\mathrm{MU} / \mathrm{m}^{3}\right)$ subject to linear constraints such as cost of production constraint, water requirement constraint; and non-negativity constraint. This optimization model is developed in such a way that determines the crops that are most suitably grown locally and their respective quantities. The rest of the crops that are not advised to be grown locally will be imported. The objective function is presented by the formula: 


$$
\operatorname{Max} Z=\sum_{i=1}^{n} p_{i} x_{i}
$$

where $\mathrm{Z}$ represents the total water productivity $\left(\$ / \mathrm{m}^{3}\right)$, i is the Index of crop type, $p_{i}$ is local farm-gate price of crop $i(\$ / \mathrm{kg}), x_{i}$ the quantity of crop $i$ to be grown locally $\left(\mathrm{kg} / \mathrm{m}^{3}\right)$, and $\mathrm{n}$ is the number of crops. The model is subjected to the following constraints:

\subsubsection{Water availability constraint}

This constraint make the production capacity water needed not exceed water availability in the project area.

$$
\sum_{i=1}^{n} w_{i} x_{i} \leq 1
$$

where $\mathrm{W}_{\mathrm{i}}$ is specific water demand (SWD) $\left(\mathrm{m}^{3} / \mathrm{kg}\right)$.

\subsubsection{Cost of production constraint}

Each crop requires a specific cost of production. These costs are disaggregated into cost of water, cost of irrigation system and its maintenance depending on the system used (surface, sprinkler and trickle) as well as other costs including fertilizers and other cultural practices. In order to grow these crops locally, they should not exceed the price of the same crop imported. This constraint is defined mathematically as follows:

$$
\sum_{i=1}^{n}\left(C_{w_{i}}+C_{i r_{i}}+C_{p_{i}}\right) x_{i} \leq P_{p_{i}}
$$

where $\mathrm{C}_{\mathrm{wi}}$ is the cost of one $\mathrm{m}^{3}$ of water $(\$ / \mathrm{Kg}), \mathrm{C}_{\mathrm{iri}}$ is the cost of the irrigation system $(\$ / \mathrm{Kg}), \mathrm{C}_{\mathrm{pi}}$ is the cost of production for crop i including fertilizers $(\$ / \mathrm{Kg})$, $\mathrm{P}_{\mathrm{pi}}$ is the price of crop i imported at Beirut port $(\$ / \mathrm{kg})$.

\subsubsection{Non-negativity constraint}

It assures the non-negativity of the study decision variable and is formulated as:

$$
x_{i} \geq 0
$$

\subsection{Data needed and analysis}

The following input data is needed to solve the mathematical model. Crops suitable to be planted in this area, Crop planting and harvesting pattern over the year, Yield of crop i per unit area $\left(\mathrm{Kg} / \mathrm{m}^{2}\right)$, Crop water requirements per growing month ( $\mathrm{mm} / \mathrm{month})$, Cost of production of one kilogram of crop $\mathrm{i}$ at the farm gate (\$), Selling price of one kilogram of crop $i$ at the farm gate in dollars, Cost of different irrigation systems per unit area $\left(\$ / \mathrm{m}^{2}\right)$, cost of $1 \mathrm{~m}^{3}$ of water $\left(\$ / \mathrm{m}^{3}\right)$, and total available water over the year. 


\subsection{Water requirement, crop yields and price}

The data generated is specific to the South Bekaa region for the 6700 hectares area specified as phase 2 area of the South Bekaa Irrigation Scheme project. Data for this research were extracted from the feasibility study of the project. The crops that were chosen totalled 43 crops. The crops were divided into three subsets: vegetables, fruit trees, and field crops. The different crops, their respective net irrigation requirements, water use efficiency, crop water yields, and farm prices are listed in table 1. Crop water yield is better defined as the quantity in kilograms of crops i produced in one cubic meter of supplementary irrigation as calculated in eqn. (6).

In addition to the cost of production of the crops, the irrigation system installed, as well as, its operation and maintenance costs and the price of water is considered. Three types of irrigation systems are usually used: surface, sprinkler, and trickle. The total annual costs are: $0.0438,0.0510$ and $0.0544 \$ / \mathrm{m}^{3} /$ year for surface, sprinkler and trickle irrigation systems, respectively.

\subsection{Solving the model}

The mathematical model was solved using the LINDO (Linear Interactive Discrete Optimizer) software after all the parameters were defined. The output data of the model are: crops to be cultivated locally; the crops to be imported, the quantity of each crop to be grown per cubic meter of water, and the maximum water productivity with respect to combination and quantities of crops produced locally.

In order to test the sensitivity of the model, different scenarios were analyzed. The first scenario was tested with respect to the production constraint, i.e. certain crops were imposed to be grown with a specific percentage for each crop, because of strategic planning issues. The second scenario dealt with water scarcity constraint. The third scenario was to test the reactivity of the model to an increase or decrease of the imported crops prices.

\section{Results}

\subsection{Optimization model results}

The initial model output is the model results without any applied constraints. The sensitivity of this model to the imposition of: production, water availability, and to the change in price of imported crops constraints will be presented and discussed later.

The initial results indicate that the maximum water productivity is 6.92032 $\$ / \mathrm{m}^{3}$ if only eight crops are grown in the project area instead of the 43 crops that are actually being grown. The eight crops are garlic, green beans, onions, radish, spinach, chickpea, lentils and janarek. The remaining 35 crops can be imported, and their cost of importation is less than their cost of production locally. This means that this irrigation project can be sustained and the saved water (virtual water) can be used to expand the irrigated area. Results also showed land use 
area for each crop. The term land use is defined as the square meters that can be irrigated by one cubic meter of water to achieve the objective function.

Table 1: $\quad$ Yield, net irrigation requirement (NIR), crop-water yield, water use efficiency (WUE) and farm price for different crops grown in Lebanon.

\begin{tabular}{|l|c|c|c|c|c|}
\hline \multicolumn{1}{|c|}{ Crop } & $\begin{array}{c}\text { Yield per } \\
\mathrm{m}^{2}\end{array}$ & NIR & $\begin{array}{c}\text { Crop Water } \\
\text { Yield }\end{array}$ & WUE & $\begin{array}{c}\text { Farm } \\
\text { Price }\end{array}$ \\
\cline { 2 - 6 }$\left(\mathrm{Kg} / \mathrm{m}^{2}\right)$ & $\mathrm{m}^{3} / \mathrm{m}^{2} / \mathrm{yr}$ & $\mathrm{m}^{3} / \mathrm{kg}$ & $\mathrm{Kg} / \mathrm{m}^{3}$ & $\$ / \mathrm{Kg}$ \\
\hline Broad beans & 0.892 & 0.132 & 0.148 & 6.778 & 0.460 \\
\hline Cabbage & 2.012 & 0.138 & 0.069 & 14.569 & 0.230 \\
\hline Carrot & 2.203 & 0.528 & 0.239 & 4.176 & 0.185 \\
\hline Cauliflower & 1.312 & 0.141 & 0.108 & 9.292 & 0.335 \\
\hline Cucumber & 1.289 & 0.276 & 0.214 & 4.679 & 0.403 \\
\hline Eggplant & 1.323 & 0.512 & 0.387 & 2.582 & 0.322 \\
\hline Garlic & 0.631 & 0.020 & 0.031 & 32.194 & 0.511 \\
\hline Green beans & 0.646 & 0.103 & 0.159 & 6.290 & 0.617 \\
\hline Okra & 0.810 & 0.310 & 0.383 & 2.611 & 0.861 \\
\hline Lettuce & 2.183 & 0.145 & 0.066 & 15.066 & 0.233 \\
\hline Melon & 1.325 & 0.400 & 0.302 & 3.311 & 0.382 \\
\hline Peas & 0.580 & 0.113 & 0.195 & 5.133 & 0.645 \\
\hline Potato (early) & 2.640 & 0.232 & 0.088 & 11.365 & 0.239 \\
\hline Radish & 1.259 & 0.047 & 0.037 & 26.902 & 0.257 \\
\hline Spinach & 1.511 & 0.073 & 0.048 & 20.841 & 0.351 \\
\hline Squash & 0.978 & 0.276 & 0.282 & 3.550 & 0.403 \\
\hline Tomato & 2.049 & 0.587 & 0.287 & 3.489 & 0.305 \\
\hline Water melon & 1.225 & 0.299 & 0.244 & 4.092 & 0.245 \\
\hline Alfalfa & 2.212 & 0.297 & 0.134 & 7.445 & 0.250 \\
\hline Barley & 0.300 & 0.134 & 0.447 & 2.235 & 0.280 \\
\hline Chickpea & 0.650 & 0.056 & 0.086 & 11.566 & 0.400 \\
\hline Lentils & 0.580 & 0.066 & 0.114 & 8.735 & 0.400 \\
\hline Lupine & 0.670 & 0.418 & 0.624 & 1.602 & 0.383 \\
\hline Dry pea & 0.650 & 0.418 & 0.643 & 1.554 & 0.533 \\
\hline Vetch & 0.750 & 0.070 & 0.093 & 10.760 & 0.283 \\
\hline Wheat & 0.300 & 0.199 & 0.663 & 1.509 & 0.313 \\
\hline Almond & 0.400 & 0.072 & 0.179 & 5.594 & 0.526 \\
\hline Apple & 1.494 & 0.797 & 0.534 & 1.874 & 0.537 \\
\hline Apricot & 0.874 & 0.275 & 0.315 & 3.178 & 0.693 \\
\hline Cherry & 1.190 & 0.254 & 0.213 & 4.685 & 0.535 \\
\hline Grape & 0.825 & 0.388 & 0.470 & 2.128 & 0.409 \\
\hline Janarek & 0.900 & 0.072 & 0.079 & 12.587 & 0.713 \\
\hline Peach & 1.193 & 0.473 & 0.396 & 2.524 & 0.679 \\
\hline Pear & 1.300 & 0.645 & 0.496 & 2.017 & 0.702 \\
\hline Plum & 1.085 & 0.275 & 0.253 & 3.945 & 0.400 \\
\hline Quince & 0.600 & 0.672 & 1.121 & 0.892 & 0.267 \\
\hline Walnut & & & & & \\
\hline
\end{tabular}




\subsection{Effect of different scenarios}

\subsubsection{Scenario I}

The model was tested to its sensitivity to alternative cropping pattern. The eight crops that were selected in the initial model output were eliminated from the cropping pattern. The model reaction was positive and selected a new array of seven crops. The new selected crops are: four vegetable crops, one field crop, and two fruit crops, with an objective function value equal to $3.319 \$ / \mathrm{m}^{3}$. In both the initial and this scenario, the model selected the least water demanding crops with competitive prices (like cabbage, cauliflower, lettuce and vetch/ winter crops and short season fruit trees like almonds and cherries).

On the other hand, for strategic planning issues, some crops need to be produced locally. Alfalfa and vetch for example are needed for animal feeding. These crops were imposed to be part of the cropping pattern solution of the model. In the initial model, the maximum water productivity is attained at 17.38 $\mathrm{m}^{2} / \mathrm{m}^{3}$ of land use Alfalfa and vetch are imposed to be produced on $10 \%$ of these $17.38 \mathrm{~m}^{2}$, divided into $57 \%\left(\right.$ one $\left.\mathrm{m}^{2}\right)$ for alfalfa and $43 \%\left(0.73 \mathrm{~m}^{2}\right)$ vetch of the $1.73 \mathrm{~m}^{2}$.area. The results obtained from this imposition were seven crops beside the two imposed crops, and the objective function became $6.306 \$ \mathrm{~m}^{3}$. Also, the same procedure was followed for fruit trees. Ten percent of the allocated land is already planted to apples, apricots and Janarek with the following allocation: 23\%: $34.7 \%$ : $42.3 \%$ of the $1.73 \mathrm{~m}^{2} / \mathrm{m}^{3}$. The objective function decreased to $4.429 \$ / \mathrm{m} 3$. By imposing certain crops as outlined before, the objective function or the maximum revenue per unit water decreased by $8.88 \%$ when alfalfa and vetch were imposed and by $36 \%$ when fruit trees were imposed.

The above results shows clearly on the effectiveness of the model in choosing a cropping pattern that will yield the best revenue per unit water. Thus, applying this model will help in sustaining the irrigation of agricultural land.

Table 2: $\quad$ Selected crops and water productivity according to different scenarios: I-a removing initial crop; I-b imposing alfalfa and vetch; and I-c imposing fruit trees.

\begin{tabular}{|r|c|c|c|c|c|}
\hline \multicolumn{2}{|c|}{ Scenario I-a } & \multicolumn{2}{c|}{ Scenario I-b } & \multicolumn{2}{c|}{ Scenario I-c } \\
\hline Crop & $\begin{array}{c}\text { Return } \\
\$ / \mathrm{kg}\end{array}$ & Crop & $\begin{array}{c}\text { Return } \\
\$ / \mathrm{kg}\end{array}$ & $\begin{array}{c}\text { Return } \\
\$ / \mathrm{kg}\end{array}$ \\
\hline Cabbage & 0.270 & Garlic & 0.521 & Garlic & 0.521 \\
\hline Cauliflower & 0.084 & Onions & 0.221 & Onions & 0.221 \\
\hline Lettuce & 0.354 & Radish & 1.625 & Radish & 1.625 \\
\hline Peas & 0.422 & Spinach & 0.366 & Spinach & 0.366 \\
\hline Vetch & 0.520 & Alfalfa & 0.555 & Chickpea & 0.505 \\
\hline Almond & 0.681 & Chickpea & 0.392 & Apples & 0.318 \\
\hline Cherry & 0.988 & Vetch & 0.154 & Apricot & 0.286 \\
\hline & \multicolumn{7}{|c|}{ Janarek } & 2.472 & Janarek & 0.587 \\
\hline $\mathrm{Z}\left(\$ / \mathrm{m}^{3}\right)=3.319$ & $\mathrm{Z}\left(\$ / \mathrm{m}^{3}\right)=6.306$ & $\mathrm{Z}\left(\$ / \mathrm{m}^{3}\right)=4.429$ \\
\hline
\end{tabular}




\subsubsection{Scenario II}

Five different quantities of available irrigation water volumes were applied to test the sensitivity of the model towards water scarcity. The amount of available water was imposed to decrease from one cubic meter in the initial model to $90 \%$, $80 \%, 70 \%, 60 \%$ and $50 \%$ (fig. 1). The reduction of available water that might be caused by dry years or any other factor is pronounced in the results obtained from the model. The decreases in water productivity are $5.25 \%, 1.68 \%, 16.67 \%$, $23.08 \%$ and $31.69 \%$ for $90 \%, 80 \%, 70 \%, 60 \%$ and $50 \%$ of available water, respectively. Also, the land use decreased from $17.39 \mathrm{~m}^{2} / \mathrm{m}^{3}$ to $9.63 \mathrm{~m}^{2} / \mathrm{m}^{3}$ in the above ranges of available water, which is an approximate decrease of $45 \%$ Moreover the cropping pattern did change. The number of selected crops decreased as water scarcity increased.

The decrease in water productivity as related to water shortage was found to be curvilinear and this relation fits the following mathematical equation:

$$
Z=-0.0255 w^{2}-0.2521 w+7.183 \quad\left(R^{2}=0.9992\right)
$$

where $\mathrm{Z}$ is the water productivity $\left(\$ / \mathrm{m}^{3}\right)$, and $\mathrm{w}$ is the fraction of available water in decimal.

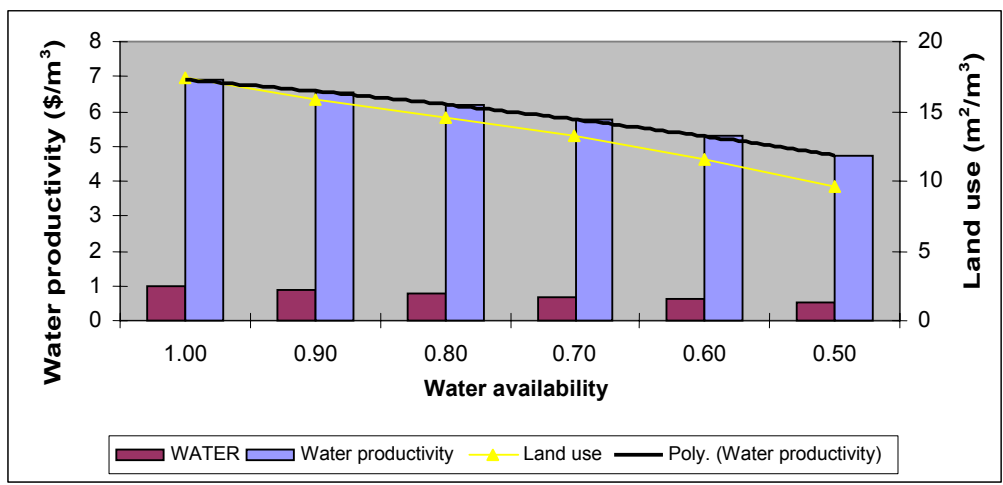

Figure 1: Changes in water productivity and land use as affected by irrigation water scarcity.

\subsubsection{Scenario III}

The import prices might be subject to increases because of increases in transportation costs due to increases in energy costs or other factors. In other cases, these prices might decrease due to competition because of globalization. Different sets of changes were considered. The import prices were subjected to decreases and increases from the initial model prices respectively by $10 \%, 20 \%$ and $40 \%$. When price decrease was imposed in the model, the number of selected crops to be grown locally was increased and the water productivity did decrease by $4.8 \%, 9.66 \%$ and $20.29 \%$ respectively for decreases of $10 \%, 20 \%$ and $40 \%$ respectively. While an increase in import price was imposed the number of selected crops by the model decreased but the water productivity 
increased from $7.253 \$ / \mathrm{m}^{3}$ at $10 \%$ import price increase to $8.166 \$ / \mathrm{m}^{3}$ at $40 \%$ increase. The trend in water productivity changes due to price increase or decrease is shown in fig. 2.

On the other hand the land use per cubic meter of water decreased from $17.388 \mathrm{~m}^{2} / \mathrm{m}^{3}$ to 13.813 as the import prices of crops decreased to $40 \%$; and reversed with increases in the import prices from initial prices. The land use was increased from 17.388 to $18.873 \mathrm{~m}^{2} / \mathrm{m}^{3}$. The water productivity-import price relationship is defined in the mathematical equation below.

$$
Z=-0.0089 p^{2}-0.3311 p+8.4 \quad\left(R^{2}=0.9831\right)
$$

where $\mathrm{Z}$ is the water productivity $\left(\$ / \mathrm{m}^{3}\right)$, and $\mathrm{p}$ is the percentage change in import prices.

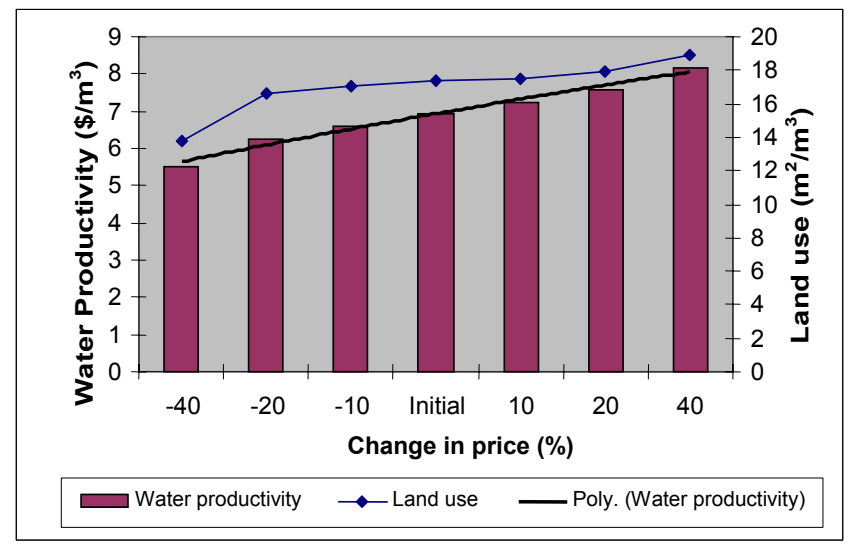

Figure 2: $\quad$ Changes in land use and water productivity with changes in import prices of crops.

\section{Discussion}

The model developed generated the maximum water productivity and selected the crops to be grown in a certain irrigated project according to the input data and assumptions previously mentioned. When high water demanding cops were imposed like alfalfa, apples, apricots, the model reacted but the water productivity decreased as presented in the results above. On the other hand, when the price of imported crops was deflated, the model reacted by choosing more crops but the water productivity decreased as well as the land used per cubic meter.

Thus, by importing the 35 crops, the net water saving will be $3408 \mathrm{~m}^{3} / \mathrm{ha}$. Therefore, in the 6700 hectares project area 22.8 million cubic meters could be saved and thus imported as virtual water, these findings are in general agreement with what reported $[7,8]$.

The results obtained in this study are not the ultimate solution for managing the use of water resources. But, they can help in strategic planning for saving 
water resources. It can help formulating long term agricultural plans in specific water scarce projects based on importing high water consuming crops with least price competitiveness, thus sustaining irrigated area. Since, population growth is continuing in the coming years, there will certainly be challenges in providing water for food security.

\section{Conclusion}

The formulated model links water productivity and virtual water and did optimize the water productivity or net return per unit of water i.e. "more revenue per drop" based on set constraints. It is certain that if the data on water requirements, yield, cropping pattern, and prices are changed, the value of water will change. The reliability of the model output depends on the reliability of the input data, which can be updated easily. The strength of the study is that by applying linear programming, it was possible to quantify the link between water scarcity or limited water availability, virtual water and sustainable irrigation.

This model can be applied to similar cases with the proper input data. Also it can simulate strategic planning for allocating the scarce water available in an irrigation scheme to keep it sustainable.

\section{References}

[1] Council for Agricultural Science Technology. 1988. Effective use of water in irrigated agriculture. Report 113. Ames, Iowa, USA.

[2] Rosegrant, M.W., Cai, X., and Cline, S.A. A Global water outlook to 2025: Averting an impending crisis. Proc. of the International Food Policy Research Institute (IFPRI), Washington, D.C., and International Water Management Institute (IWMI), Colombo, Sri Lanka, 2002.

[3] Allan, J.A. Virtual water: A long term solution for water short Middle Eastern economies? Paper presented at the British Association Festival of Science, University of Leeds, 1997.

[4] Bouwer, H. Integrated water management: emerging issues and challenges. Agricultural Water Management 45: 217 -228, 2000.

[5] Nimah, M.N., M.N. Hamed, J. Haddad and M. R. Darwish. Water and food security, optimal allocation of water resources in agriculture: a case study from Lebanon. The Land 5.2: 119-136, 2001.

[6] Moukarzel, S. N., and Nimah, M. N. Virtual Water and Water Productivity as a Strategic Plan for Water Governance in the ESCWA region. Proc. of the Seminar on Water Governance: Role of stakeholders and civil society institutions in water management. 14-15 Nov, 2005. Beirut, Lebanon.

[7] Allan, J.A. Virtual Water Eliminates water wars? A case study from the Middle East; in Hoekstra ed. (2003).

[8] Oki, T.; Sato, M.; Kawamura, A.; Miyake, M.; Kanae, S., and Musiake, K. Virtual water trade to Japan and in the world. Phys. Chem. Earth, 2003 . 